\title{
Laparoscopic dissection of the ureter for radical laparoscopic hysterectomy
}

Received: 6 March 2005 / Accepted: 10 May 2005/Published online: 16 July 2005

(C) Springer-Verlag Berlin / Heidelberg 2005

\begin{abstract}
The most important step in radical hysterectomy is freeing the ureter from the anterior parametrium. In this paper we describe our modified technique for freeing the ureter from the anterior parametrium for a Piver II-III radical hysterectomy by means of pure laparoscopic surgery. Our series consists of seventeen patients undergoing laparoscopic hysterectomy. In evaluating the technique, we considered its feasibility, the operating time, the time for complete preparation of the ureter as measured on the videotapes of the procedures, the short-term complication rate, and the length of hospital stay. Thirty-one ureters were unroofed; in three patients, monolateral dissection was performed. The median time of the surgical procedures was $182 \mathrm{~min}$ (range 110-255). The median time to unroof the ureter on one side was 14 min $35 \mathrm{~s}$ (range $10 \mathrm{~min} 15 \mathrm{sec}-63$ min). No patient had ureteronephrosis at ultrasound at control. Even if the experience with this technique is limited, the almost constant time to free the ureter shows that, laparoscopically, it can be performed with relative ease, particularly in patients without prolapse.
\end{abstract}

Keywords Laparoscopic surgery - Laparoscopicassisted radical hysterectomy $\cdot$ Laparoscopic radical hysterectomy · Cervical cancer · Endometrial cancer

\section{Introduction}

Laparoscopic-assisted radical hysterectomy for cervical cancer has been developed in the last decade [1-10]. Total laparoscopic radical hysterectomy was pioneered

E. Volpi $(\bowtie) \cdot$ A. Ferrero $\cdot$ A. P. Carus $\cdot$ E. Jacomuzzi P. Sismondi

Department of Gynecological Oncology,

University of Turin, Ospedale Mauriziano "Umberto I",

Largo Turati 62, 10100 Torino, Italy

E-mail: medvolp@libero.it

Tel.: + 39-11-3248345

Fax: + 39-11-359328 by Nezhat et al. [6, 11] and Canis et al. [12], but the completion of radical surgery laparoscopically rather than vaginally is described by fewer authors [13-17].

The most important and difficult step in completing radical hysterectomy is "unroofing" the ureter and freeing it from the anterior parametrium. Whereas the technique for this step is well established by the vaginal approach, the laparoscopic technique has not been extensively described in detail. Most physicians free the ureter vaginally [1-10]. However, to accomplish such a procedure, experience is needed in radical vaginal surgery.

The aim of this paper is to describe our technique for freeing the ureter from the anterior parametrium for a Piver II-III radical hysterectomy by means of pure laparoscopic surgery.

\section{Materials, methods, and surgical technique}

Our series consists of seventeen patients undergoing laparoscopic hysterectomy from January 2002 to April 2004. The indications for radical hysterectomy (type II) were endometrial cancer in 12 cases (stage I, 9; stage II, 3 ) and cervical cancer in two cases (stage Ia2). Patients with stage I endometrial cancer were enrolled in an Italian multicenter trial comparing types I and II hysterectomy. In two cases of infiltrating endometriosis and in one case of myoma, the ureter was prepared as required for radical surgery. Patient characteristics are presented in Table 1.

All of the patients underwent surgery according to the technique described below.

In evaluating the technique, we considered its feasibility, the operating time, the time for complete preparation of the ureter as measured on the videotapes of the procedures, the short-term complication rate, and the length of hospital stay. All patients had a control sonography at the first postoperative visit, 1 month after surgery, to evaluate ureteral complications. 
Table 1 Patient characteristics

Characteristics

Age (years)

Endometrial cancer stage I

Endometrial cancer stage II

Cervical cancer stage Ia2

Endometriosis

Myoma

Body mass index

Presence of prolapse

Median 58; range 33-73

9

3

2

2

1

Median 26.53; range 19.78-39.55

Surgical technique

The patient is placed in lithotomy position. Two monitors placed at the patient's feet are used for the surgery. No uterine cannulation is used, especially in gynecologic malignancies such as endometrial cancer. The uterus is mobilized exclusively with intraabdominal instruments. Moreover, our technique of uterine artery coagulation at its root, without cutting, gives us a further traction method.

Pneumoperitoneum is induced with semi-open direct trocar umbilical insertion according to our previously described technique [18]. In this approach, the peritoneum is first opened, and a trocar is then directly inserted without insufflation. An incision is made at the deepest point of the umbilical scar down to the peritoneal membrane, which is entered to a depth of 1-2 mm. The trocar is then directly inserted. This technique is faster and easier than upper-quadrant entry. In our published series, no major complication was observed, and the approach was changed to Palmer's upper quadrant entry with a Veress needle in only one of 184 patients.

The ancillary trocars are placed lateral to the epigastric artery at about two fingers' width from the anterior superior iliac spine; a third ancillary trocar is placed centrally. The preliminary step is the preparation of the extraperitoneal hysterectomy according to Kadar [19]. The round ligament is opened at the pelvic side wall, but little or no dissection of the bladder is performed. After the broad ligament is opened and the ureter is dissected at the pelvic brim, the pararectal space is formed. The internal iliac artery is visualized, and the ureter is followed to the cross with the uterine artery. The medial leaf of the broad ligament is left intact. After identification of the uterine artery at its root, bipolar coagulation of the vessel is performed. Frequently, the uterine veins are also visualized and coagulated. However, the whole vascular bundle is respected, without cutting. To dissect the farther part of the ureter, the forceps contralateral to the side of dissection strongly pull the uterus at the round ligament or at the uteroovarian ligament so that the ureter can be seen in its length. The two other instruments for freeing the ureter from the anterior parametrium should now be scissors or a dissecting forceps and bipolar coagulation. The dissection - as much as the operator can perform - must

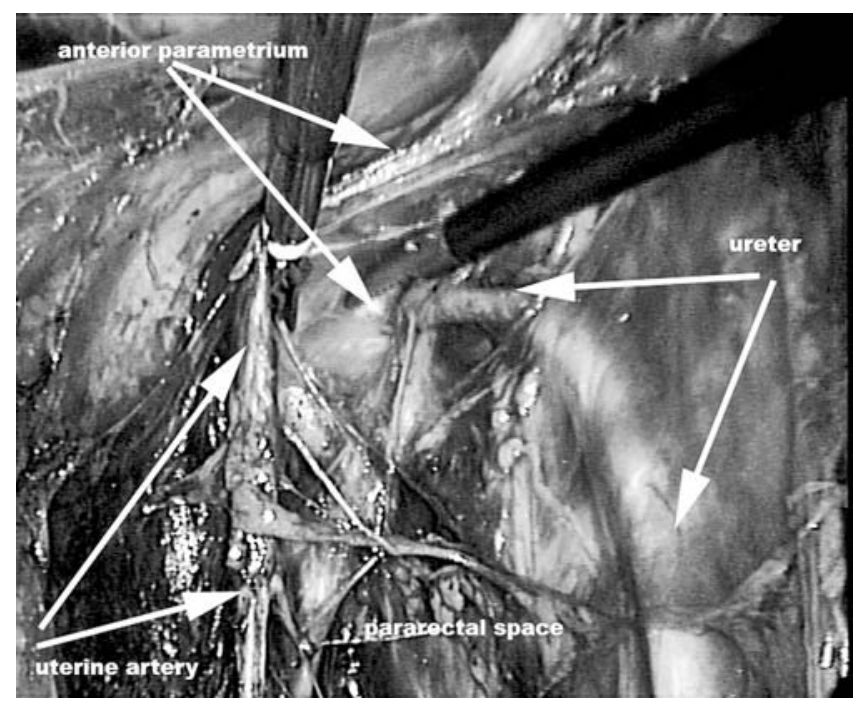

Fig. 1 The left ureter is separated from the uterine artery, which is kept intact and displaced by the bipolar coagulator while the forceps detaches the ureter from the anterior parametrium

follow the ureter directly on its adventitia into the anterior parametrium, starting from its lateral and superior aspect and advancing toward the bladder (Figs. 1 and 2). The uterine artery must not be severed at this phase. The upper part of the anterior parametrium is gently separated from the ureter, and the tunnel is formed, keeping all the tissue above.

When the ureter changes direction in front of the vagina and the operator cannot follow it anymore, the anterior parametrium is then coagulated and severed. The uterine artery is kept for traction. At this time only, the bladder can be lowered as much as needed. Only the medial part of the bladder pillar is now left in place and dissected according to the type of hysterectomy

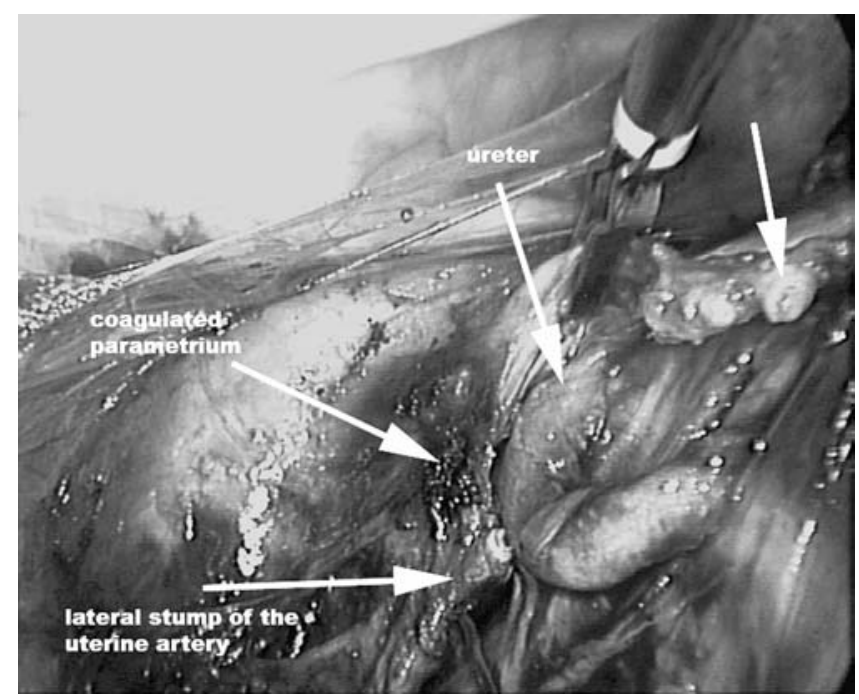

Fig. 2 The stumps of the left uterine artery are visible, and almost all the ureter is freed 


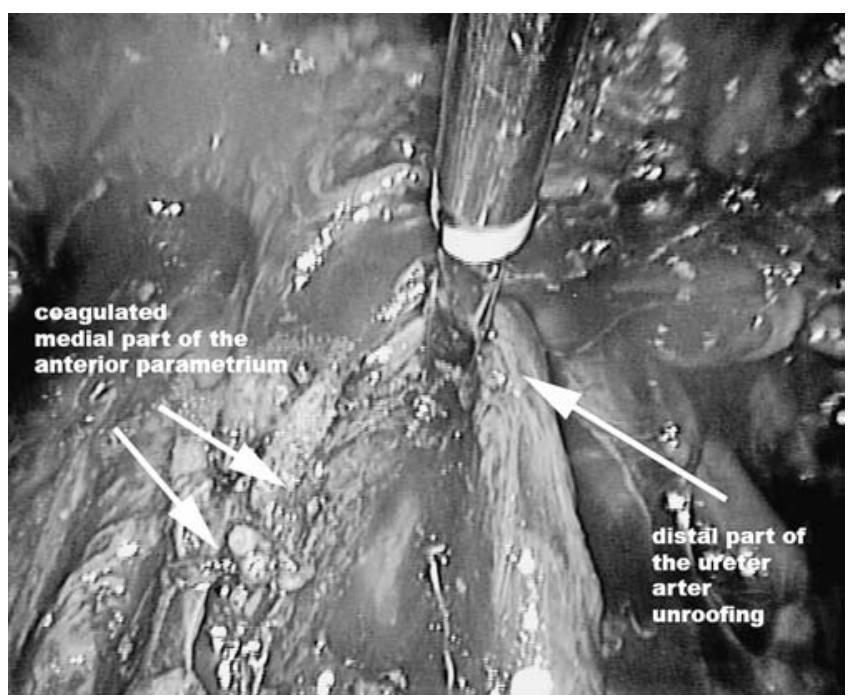

Fig. 3 On the right, the distal part of the ureter is visible during dissection from the medial bladder pillar

requested (Fig. 3). The lateral parametrium is then treated by means of bipolar coagulation, and hysterectomy is completed vaginally.

\section{Results}

Thirty-one ureters were unroofed; in three patients, monolateral dissection was performed. The procedures performed in the patients are shown in Table 2.

The median time of the surgical procedures was 182 min (range 110-255 min).

The median time to unroof the ureter on one side was $14 \mathrm{~min} 35 \mathrm{~s}$ (range $10 \mathrm{~min} 15 \mathrm{~s}-63 \mathrm{~min}$ ).

In two patients with uterine prolapse and endometrial cancer, the procedure was more difficult because of the ureter's winding course. The most difficult procedure was in a patient with deep endometriosis who had stenosis of the ureter in the anterior parametrium.

Table 2 Procedures performed and results

Associated procedures/evaluated factors

Pelvic lymphadenectomy

Paraaortic lymphadenectomy

Omentectomy

Appendectomy

Operating time

Time for unroofing

Conversion

Fever

Hospital stay (days)

Ureteronephrosis
No conversion to laparotomy was needed. No shortterm important complication was observed. Fever (three cases) was treated with antibiotics. One patient had a hematoma of the abdominal wall, with no consequence 7 days after surgery. No second surgery was performed in any of the patients.

The patients' median hospital stay was 3 days (range $2-10$ ). One patient had nephrotic syndrome and, having had extensive surgery, was observed for 6 days. One of the patients with endometriosis had urinary retention because of deep dissection of the pelvis and was released on the 10th day. No patient had ureteronephrosis at ultrasound at control.

\section{Discussion}

Radical laparoscopic hysterectomy has been only recently introduced and is not yet a usual procedure. Historically, dissection of the ureter from the vagina has been performed by a surgeon skilled in vaginal procedures, but laparotomy has progressively gained popularity because of the possibility of lymphadenectomy. Most of the authors performing laparoscopic-assisted radical hysterectomy free the ureter by the vaginal approach [1-10]. The most important difference between laparoscopic and vaginal radical surgery lies in this step of the procedure, while the resection of the lateral parametria appears less critical.

The previous reports of radical laparoscopic surgery briefly explain the unroofing of the ureter; generally, the preparation is similar to the description of laparotomic radical surgery in which the uterine artery is cut before the anterior parametrium is entered $[6,11-17,20]$. Then traction is performed on the uterine stump, distorting the ureter and its roof. With this technique it is necessary to have already lowered the bladder below the level of the ureters to be able to find their paths to the bladder. The technique we describe is original and relies on the advantages of laparoscopy: The first advantage is magnification, the second is $\mathrm{CO}_{2}$ pressure, and the third and, we believe, the most important is that the vessels are left intact, and the ureter is visualized in its length and not from above. This allows following the straightened ureter into the anterior parametrium, which can be aligned with the operator without difficulty. The uterine artery is coagulated, but not cut, before taking access to the ureteral tunnel. Then the ureter is freed from the surrounding tissue, working directly on the adventitia of the ureter and dissecting cautiously. We frequently use the tip of the bipolar coagulator, which has the exact elasticity for dissecting the tissue without using strength in opening the forceps. It is not even necessary to detach the bladder from the vesicovaginal fascia because the work is performed directly on the ureter. Only when the ureter cannot be followed further in the anterior parametrium does the bladder need to be dissected. The procedures we performed were class II hysterectomies, but the ureter can be freed from the inferior part of the anterior 
parametrium in type III hysterectomies as well. All hemostasis is based on bipolar coagulation. We believe that using the bipolar forceps allows sure control of the vessel and dissection at the same time, whereas stapling is much more expensive $[16,17]$ and needs larger ports.

The median time to free the ureter on one side was 14 min $35 \mathrm{~s}$, but we had difficulties in the patients with uterine prolapse because the usual course of the ureter changes, and the ureter bends upwards. We believe that this is an acceptable time in the operation as a whole, and the median total time for surgery completion was not long. In no patient did we need to convert to laparotomy, even if the time was longer. In one patient with endometriosis and ureteral stenosis, the time to free the ureter was about $1 \mathrm{~h}$, and the technique was much more complex because of fibrosis. Interestingly, the time was almost constant in all procedures, except for the difficult cases. Technically, we never needed to increase the port number, as Canis et al. suggest [20], or place ureteral catheters, as Lee et al. suggest [4].

A large number of patients were relatively obese, but no difficulty was due to the weight of the patients with BMI > 25. Eltabbakh et al. [21] have shown that endometrial cancer can be correctly treated by means of laparoscopic surgery in obese patients as well.

A rate of ureteral complications ranging from 0 to $6 \%$ has been reported $[2,17]$. Even if we realize that ureteral fistula is a relatively rare complication of type II hysterectomy and that our series was too small to show an increase in this type of complication, nevertheless we report that we did not observe one. In a series of 200 cases, Hertel et al. [2] described a significant decrease in complications with increase of the learning curve. We implemented our training in vaginal and laparoscopic surgery before the development of this technique. We also believe that laparoscopy is superior to the vaginal approach from the teaching point of view and may be used in cases in which the vaginal approach is not indicated. On the contrary, radical vaginal trachelectomy is only feasible from below.

In conclusion, we have herein described our technique for unroofing the ureter. This is the most important step for accomplishing radical hysterectomy by means of endoscopic surgery. Even though the experience is limited, the almost constant time to free the ureter shows that, laparoscopically, it can be performed with relative ease, particularly in patients without prolapse.

\section{References}

1. Dargent D (1998) Laparoscopically assisted radical hysterectomy (distal "celio-Schauta" procedure). In: Querleu D, Dargent $\mathrm{D}$, Childers $\mathbf{J}$ (eds) Laparoscopic surgery in gynecologic oncology. Blackwell Science, London, pp 63-69

2. Hertel H, Koehler C, Michels W, Possover M, Tozzi R, Schneider A (2003) Laparoscopic-assisted radical vaginal hysterectomy (LARVH): prospective evaluation of 200 patients with cervical cancer. Gynecol Oncol 90:505-511

3. Kadar N (1995) Laparoscopic-vaginal radical hysterectomy. In: Kadar N (ed) Atlas of laparoscopic pelvic surgery. Blackwell Science, Oxford, pp 231-250

4. Lee C-L, Huang K-G, Wang C-W, Huang H-Y, Lai Y-M, Lai C-H, Soon Y-K (1997) New approaches in laparoscopically assisted vaginal hysterectomy. Int Surg 82:266-268

5. Malur S, Possover M, Schneider A (2001) Laparoscopically assisted radical vaginal versus radical abdominal hysterectomy type II in patients with cervical cancer. Surg Endosc 15:289292

6. Nezhat CR, Nezhat FR, Burrell MO et al (1993). Laparoscopic radical hysterectomy and laparoscopically assisted vaginal radical hysterectomy with pelvic and paraaortic node dissection. J Gynecol Surg 9:105-120

7. Park CT, Lim KT, Chung HW, Lee KH, Seong SJ, Shim JL, Kim TJ (2002) Clinical evaluation of laparoscopic-assisted radical vaginal hysterectomy with pelvic and or paraaortic lymphadenectomy. J Am Assoc Gyn Laparosc 9:49-53

8. Possover M, Krause N, Schneider A (1998) Identification of the ureter and dissection of the bladder pillar in laparoscopic-assisted radical hysterectomy. Obstet Gynecol 91:139-143

9. Renaud MC, Plante M, Roy M (2000) Combined laparoscopic and vaginal radical surgery in cervical cancer. Gynecol Oncol 79:59-63

10. Schneider A, Possover M, Kamprath S, Endisch U, Krause N, Noeschel H (1996) Laparoscopy-assisted radical vaginal hysterectomy modified according to Schauta-Stoeckel. Obstet Gynecol 88:1057-1060

11. Nezhat CR, Burrell MO, Nezhat FR, Benigno BB, Welander CE (1992) Laparoscopic radical hysterectomy with paraaortic and pelvic node dissection. Am J Obstet Gynecol 166:864-865

12. Canis M, Mage G, Wattiez A, Pouly J-L, Manhes H, Bruhat M-A (1992) Vaginally assisted laparoscopic radical hysterectomy. J Gynecol Surg 8:103-106

13. Hsieh YY, Lin WC, Chang CC et al (1998) Laparoscopic radical hysterectomy with low para-aortic, subaortic and pelvic lymphadenectomy. Results of short-term follow-up. J Reprod Med 43:528-534

14. Kim DH, Moon JS (1998). Laparoscopic radical hysterectomy with pelvic lymphadenectomy for early, invasive cervical carcinoma. J Am Assoc Gynecol Laparosc 5:411-417

15. Sedlacek TV, Campiom MJ, Hutchins RA, Reich H. (1994) Laparoscopic radical hysterectomy: a preliminary report. J Am Assoc Gynecol Laparosc 1:S32

16. Spirtos NM, Eisenkop SM, Schlaert JB, Ballon SC (1996). Laparoscopic radical hysterectomy (type III) with aortic and pelvic lymphadenectomy in patients with stage I cervical cancer. Am J Obstet Gynecol 174:1763-1767

17. Spirtos NM, Eisenkop SM, Schlaert JB, Ballon SC (2002) Laparoscopic radical hysterectomy (type III) with aortic and pelvic lymphadenectomy in patients with stage I cervical cancer: surgical morbidity and intermediate follow-up. Am J Obstet Gynecol 187:340-348

18. Volpi E, Sismondi P (2002) Semi-open direct trocar insertion method for induction of pneumoperitoneum at laparoscopy. Gynaecol Endosc 11:197-200

19. Kadar N (1995) The extraperitoneal technique. In: Kadar N (ed) Atlas of laparoscopic pelvic surgery. Blackwell Science, Oxford, pp 101-114

20. Canis M, Wattiez A, Mage G, Mille P, Pouly J-L, Bruhat M-A (1998) Laparoscopic radical hysterectomy for cervical cancer. In: Querleu D, Dargent D, Childers J (eds) Laparoscopic surgery in gynecologic oncology. Blackwell Science, London, pp 70-77

21. Eltabbakh GH, Shamonki MI, Moody JM, Garofano LL (2002) Hysterectomy for obese women with endometrial cancer: laparoscopy or laparotomy? Gynecol Oncol 78:329-335 